\title{
Sir James Crichton-Browne (1840-1938): pioneer neurologist and scientific drop-out
}

\author{
E H Jellinek DM FRCP
}

J R Soc Med 2005;98:428-430

In an era when surgery was hazardous, psychiatry custodial, and medicine at best pastoral, James Crichton Browne in his ten years as director of the West Riding Lunatic Asylum at Wakefield initiated a scientific approach to the brain and its diseases and later gave it a voice by co-founding Brain, the first journal of what would now be called the neurosciences.

Crichton-Browne has been the subject of a long and fully referenced study by the historian Michael Neve and the psychiatrist Trevor Turner, ${ }^{1}$ including his life as alienist, as Lord Chancellor's Visitor in Lunacy, and as prolific activist on social, medical and literary matters. But they are brief on his research efforts at the Asylum at Wakefield between his 26th and 37th years, and then his co-founding of Brain which furthered the schism of neurology from psychiatry.

He was born at Edinburgh into a cultured professional setting, and was given his second name Crichton to mark the munificence of his godmother, Mrs Elizabeth Crichton, who had given $£ 100000$ to found an asylum at Dumfries in 1839. After visiting James' father, WAF Browne, at the asylum at Montrose, the oldest Scottish asylum, where he had published What asylums were, are, and ought to be in 1838, she had installed him as the first superintendent of the new Crichton Royal Institution at Dumfries in the following year. $^{2}$

The young James read medicine at Edinburgh where he worshipped Thomas Laycock (1812-1876), the professor of medicine who had previously had John Hughlings Jackson as apprentice at York.

\section{THE WEST RIDING LUNATIC ASYLUM AT WAKEFIELD}

James Crichton Browne qualified in 1861, and after brief stints in English provincial asylums was made medical director of the West Riding Lunatic Asylum at Wakefield in Yorkshire in 1866, aged 25. During his decade there he converted it from an asylum to a reasonably staffed hospital, with more medical, nursing and lay personnel, all financed by local government. Initially all patients were paupers who had been committed, but later they included voluntary paying inmates. ${ }^{3,4}$

7 Oxgangs Road, Edinburgh EH10 7BG, Scotland, UK
He attracted local medical support, including his former Edinburgh near contemporary Clifford Allbutt, physician at the newish Leeds medical school. He enforced necropsies as a routine, and started a laboratory for anatomy, neuropathology and histology (by Herbert Major and W Bevan Lewis), and for animal experimentation by his juniors and visitors, such as David Ferrier from King's College, London. The original 1815 structure was enlarged, and the drains were improved after lethal in-house epidemics.

James copied his father's 'moral' treatment at the Crichton Royal - that is, no restraints, but diversional and occupational therapy with sedation as necessary, and trials

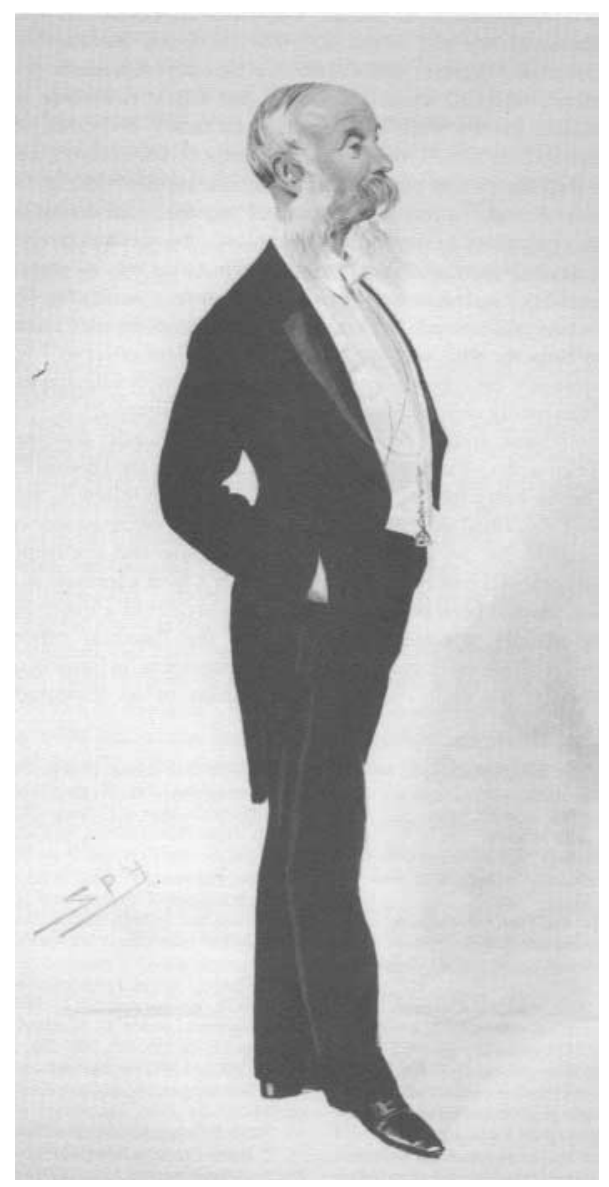

Figure 1 Cartoon of Sir James Crichton-Browne by 'Spy' (L Ward). Frontispiece of Sir J Crichton-Browne's Victorian Jottings (London: Etchells \& MacDonald, 1926) 
of just about all potentially neuroactive medicaments and physical agents of that time, by himself, and by his juniors and visiting doctors, often after self-medication.

He insisted on proper records, and started annual open days and conversaziones for the local quality, with distinguished visiting speakers.

\section{THE MEDICAL REPORTS}

In his sixth year (1871) he began publishing the annual Medical Reports: the six volumes (1871-1876) each had 10-15 monographs by some 40 authors, most from the asylum. ${ }^{5}$ James wrote a few short prefaces, the first being a refutation of the gibe that most asylums were scientifically sterile; he had an article by himself in each volume.

His 'Cranial injuries and mental diseases' in the first two volumes ranges from a kind of epidemiology of craniocerebral trauma - birth trauma, Yorkshire coal-mining, rugby football, etc - to its symptoms and management, and to remote effects from brain softening, sclerosis and cysts, as seen in his 1500 necropsies at the asylum.

His other big neuropathological study in Volume 6 concerns 'General paralysis' with colour diagrams of the mainly frontal siting of the chronic inflammatory lesions of neurosyphilis, a major cause of asylum admissions at that time.

His shorter articles are on the use of amyl nitrite in the treatment of status epilepticus (Volume 3), and on the features and causes of 'acute dementia', recte confusional states, in Volume 4. He must have been one of the first to use clinical photography-borrowed, and acknowledged, by his father's friend Charles Darwin in his illustrations for The Expression of the Emotions in Man and Animals in 1872-'I can hardly overestimate the value of his [JCB's] assistance.'

An interesting review of aphasia in Volume 2 by his father, WAF Browne, traces the link between phrenology and the emerging cortical localizations of the 1870s.

Earlier British asylum reports, such as his father's from the Crichton Royal, had confined themselves to asylum statistics, and perhaps psychiatric topics by the superintendent, but most of the contents of his Reports were by a new brand of neuroscientists, his juniors and friends, some from afar. The most famous was the clinician J Hughlings Jackson, who had practised for over a decade at the new Hospital for the Epileptic and Paralysed (later the National Hospital, Queen Square) and at the London Hospital; he had one or two papers in the third (1873) and in all the later volumes of the Reports. The first, in Volume 3, had been an attempt to match Ferrier's cortical localization experiments with his clinical data, 'Observations on the localisation of movements in the cerebral hemispheres'. His classifications and definitions are not easy to follow, particularly his speculation on language. But his lucid accounts of mental disorders with, and after, seizures in Volumes 5 and 6 are classics.

The second contributor of neurological fame, who had also been influenced by Laycock, was David Ferrier (18431928). He came from King's College, London, where he was professor of forensic medicine, to experiment in the asylum laboratory at Wakefield in an elaboration of the work of Fritsch and Hitzig. In 'Experimental researches in cerebral physiology and pathology' (Volume 3) he states: 'I have to thank Dr Crichton Browne for kindly placing at my disposal the resources of the Pathological Laboratory of the West Riding Asylum with a liberal supply of pigeons, fowl, guinea-pigs, rabbits, cats and dogs for my research'. His paper ranges out into a much wider discussion of brain physiology and the relevance of Hughlings Jackson's clinical views. Ferrier himself in Volume 4 (1874) attempted five clinicopathological correlations in his 'Pathological illustrations of brain function'.

Two contributors achieved wider renown. Clifford Allbutt (1836-1925) wrote on the ophthalmoscopy he had done at the asylum, and, more diffidently, in Volume 2, on his electrical treatment ${ }^{6}$ of about 20 asylum patients with a constant current from fifteen cell batteries, applied to the head or neck for 10-15 seconds. Sir Clifford ended as regius professor at Cambridge, and is remembered for his thermometry.

The other more general achiever was T Lauder Brunton (1844-1916) who had discovered the value of amyl nitrite in angina in 1867; in Volume 4 of the Reports, writing from Barts, he briefly noted his failure to produce inhibition in kittens by stimulation of the brain with electricity in the Wakefield laboratory, but discoursed amusingly, at length, on inhibition, both peripheral and central.

Neuropathology was treated in five papers by Herbert C Major, who followed Crichton Browne as the asylum director, and in one by $\mathrm{W}$ Bevan-Lewis, also a later director.

All six volumes contain optimistic but unconvincing papers on treatment trials by juniors, on madness, depression, organic brain disease and epilepsy with drugs (some parenterally) and agents then known to have some effect on the nervous system - alcohol, morphine, cannabis, hyoscine, ergot, conia, nicotine, chloral, ether, nitrous oxide, and electricity, all recorded as inspired by Crichton Browne.

\section{BRAIN}

The West Riding Lunatic Asylum Reports ceased in 1876 when Crichton Browne left Wakefield to become Lord Chancellor's Visitor in Lunacy, ${ }^{1}$ but this allowed him to co-found and co-edit Brain in 1878 with J C Bucknill, D Ferrier and J Hughlings Jackson. Brain was the world's first 
neuroscientific journal, and became probably the most influential. Similar (non-psychiatric) journals followed in German (1879) and French (1880). One suspects that Crichton-Browne (the hyphen in the name appeared first in Volume 1 of Brain in 1878) was more active than the other three; Bucknill was entirely an alienist in his practice and writings, and had been the founder-editor of the Journal of Mental Science (originally the Asylum Journal of Mental Science) from 1853 to 1862. Hughlings Jackson was the most inspirational of the four but rather chaotic. ${ }^{7}$ Ferrier was deeply involved in experimental and clinical neurology and teaching. ${ }^{8}$ One suspects that Crichton-Browne's Visitorship would have allowed more time to edit; his three or so journeys a week to inspect Chancery lunatics throughout England and Wales ${ }^{1}$ left time to do much else, including the treasurership of the Royal Institution from 1889 to 1926.

Brain was similar to the West Riding Lunatic Asylum Reports in its range of contents, but more international, with, for instance, a paper in Volume 7 (1886) by Sigmund Freud on neurohistological staining. Unlike Ferrier and Jackson, Bucknill and Crichton-Browne contributed almost no articles to Brain. The four handed over the tenth volume of Brain in 1889 to the new London Neurological Society as its organ, under the editorship of A de Watteville, who remained in post until 1900. Crichton-Browne continued as the peripatetic Visitor in Lunacy till he was 82 in 1922. He published entertaining books of anecdote, literary and social comment and criticism into the last year of his life, his ninety-eighth. ${ }^{1}$

\section{REFERENCES}

1 Neve M, Turner T. What the doctor thought and did: Sir James Crichton-Browne (1840-1938). Med History 1995;39:399-432

2 Scull A, Mackenzie C, Hervey N. The Masters of Bedlam: the Transformation of the Mad-Doctoring Trade. New York: Princeton University Press, 1996

3 Ashworth AL. Stanley Royd Hospital, Wakefield-150 years, a History. London: Berrico, 1977

4 Shaw Bolton J. The evolution of a mental hospital in Wakefield 18181928. J Ment Sci 1928;74:587-633

5 Crichton Browne J, ed. West Riding Lunatic Asylum Reports; 6 volumes. London: Churchill, 1871-76

6 Beveridge AW, Renvoize EB. Electricity, a history of its use in the treatment of mental illness in Britain during the second half of the 19th century. Br J Psychiatry 1988;153:157-62

7 Taylor J. Neurological Fragments by J Hughlings Jackson with Biographical Memoirs by Sir J Hutchinson \& C Mercer. Oxford: Oxford University Press, 1925

8 Sherrington CS. Sir David Ferrier, obituary. Proc $R$ Soc Lond 1928;103:vii-xiv 